\title{
Islanding Detection Method for Inverter-based Distributed Generation Systems using a Signal Cross-correlation Scheme
}

\author{
Byung-Yeol Bae*, Jong-Kyou Jeong**, Ji-Heon Lee**, and Byung-Moon Han ${ }^{\dagger}$ \\ $\dagger^{* *}$ Dept. of Electrical Engineering, Myongji University, Yongin, Korea \\ ${ }^{*}$ LSIS R\&D Center, LS Industrial Systems Co., Ltd., Anyang, Korea
}

\begin{abstract}
This paper describes the development of a new islanding detection method for inverter-based distributed generation systems, which uses a signal cross-correlation scheme between the injected reactive current and the power frequency deviation. The proposed method injects $1 \%$ of the reactive current to the rated current which brings about a negligible degradation of the power quality. It discriminates the islanding state, when the calculated cross-correlation index is larger than 0.5 . The operational feasibility was verified through computer simulations with PSCAD/EMTDC software and experimental research with a hardware prototype. The proposed method can detect the islanding state without degrading the power quality at the point of common connection. Further study is required to overcome the cancellation of the injected reactive current from multiple distributed generation units interconnected with the utility grid.
\end{abstract}

Key Words: Active Method, Cross-correlation, Inverter-Based DG(Distributed Generator), Islanding detection, NDZ(NonDetection Zone), PCC(Point of Common Connection), Reactive Current Injection

\section{INTRODUCTION}

Due to environmental issue and energy exhaustion, various distributed generation systems have come into wide use in many countries. Typical distributed generation systems are wind power generation, photovoltaic power generation, fuel cell power generation, and micro-turbine power generation. A DG (distributed generator) is normally connected together with the existing utility grid at one point so that they are sharing the local load.

Islanding detection is a key issue when a DG works in connection with the power grid. In the early days, a passive method which checks the variation of voltage and frequency at the PCC (point of common connection) was generally used. However, when the mismatch between the generated power and the size of load is very small, it is not easy to detect the islanding state because the variations in voltage or frequency at the PCC are also very small [1]-[4]. Therefore, various studies have been carried out to find an accurate detection method with an active scheme.

One typical active method is to inject reactive power from the DG to the interconnected power grid and to check the frequency deviation. This method is widely applied because

\footnotetext{
Manuscript received May 6, 2010; revised Sep. 28, 2010

$\uparrow$ Corresponding Author: erichan@mju.ac.kr

Tel: +82-31-330-6366, Fax: +82-31-330-6816, Myongji Univ.

* LSIS R\&D Center, LS Industrial Systems Co., Ltd., Anyang, Korea

** Dept. of Electrical Engineering, Myongji University, Yongin, Korea
}

the DG is normally interconnected through an inverter, which easily generates reactive power [5]-[9].

However, with this method it is not easy to detect the islanding state too if the magnitude of the injected reactive power is not large enough. Therefore, the magnitude of the injected reactive power is critical for detection because a large magnitude of injected reactive power brings about the degradation of power quality at the PCC. The magnitude of the injected reactive power is normally several $\%$ of the rated power of distributed generation system [10], [11].

This paper proposes a new islanding detection method in which the signal cross-correlation index between the injected reactive current and the power frequency deviation is calculated to discriminate the islanding state. The proposed method injects a $20 \mathrm{~Hz}$ triangular waveform of $1 \%$ reactive power to the rated power of a DG so as to minimize the power quality degradation due to the injection of reactive power.

\section{Islanding Detection PRoblem}

Fig. 1 shows a typical single-line diagram for a distributed generator that is interconnected with a utility grid and a local load.

When the utility grid operates in normal mode, the demanded power at the load is shared by the DG. However, when a fault occurs in the utility grid, the upper breaker is opened and the rest of the system operates in islanded mode. The demanded power at the load is only supplied by the DG. 


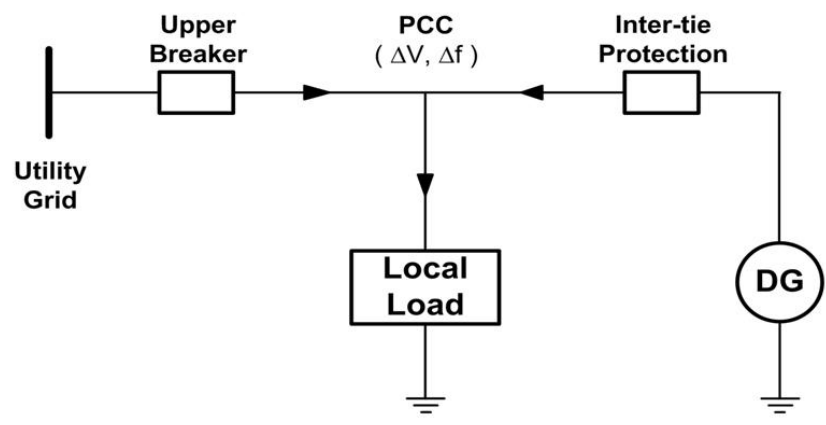

Fig. 1. Grid-tied Distributed Generation System.

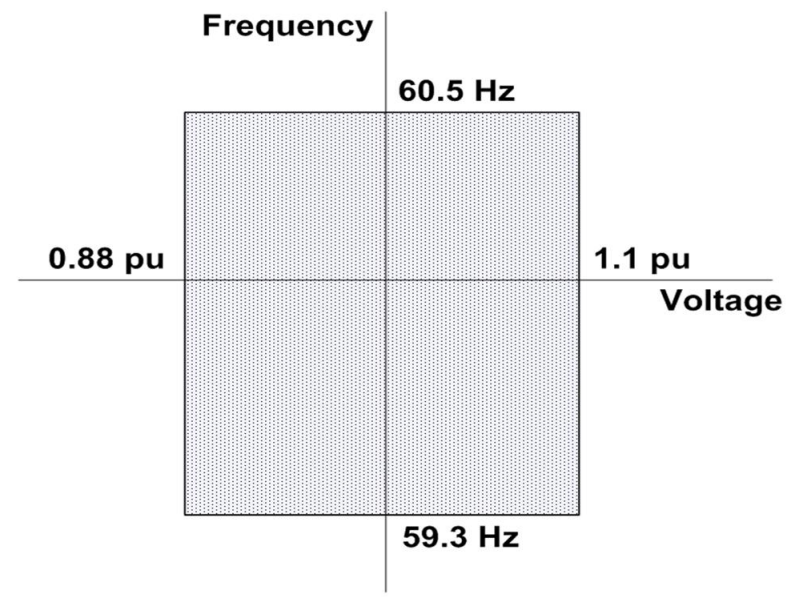

Fig. 2. Non-Detection Zone in IEEE std 929-2000.

If the demanded power at the load is much larger than the supplied power from the DG, the magnitude of the voltage and frequency at the PCC decreases rapidly. In the opposite case, the magnitude of the voltage and frequency at the PCC increases rapidly. So, it is easy to detect the islanding state by sensing voltage and frequency deviations.

However, if the demanded power at the load is almost the same as the supplied power from the DG, it is not easy to detect the islanding state by checking the voltage and frequency deviations.

Therefore, the ease of islanding detection depends on the amount of frequency and voltage deviations. If the frequency and voltage deviations are located within a certain region, it is impossible to detect the islanding state. IEEE standard 9292000 defines this region as the NDZ (non-detection zone), which is described in Fig. 2. According to this standard, the NDZ is defined by the region where the voltage and frequency at the connection point are located between $0.88<V_{P C C}<$ $1.10 \mathrm{pu}$, and between $59.3<f_{P C C}<60.5 \mathrm{~Hz}$ without escaping for $0.5 \mathrm{sec}$ [4].

Many researchers have already developed many new methods to detect the islanding state when the frequency and voltage deviations at the PCC are located in the NDZ.

\section{GRID-TIED DG WITH AN INVERTER}

Fig. 3 shows a configuration of a DG with an inverter which is interconnected with the utility grid. The voltage source inverter operates in a synchronized manner with the utility

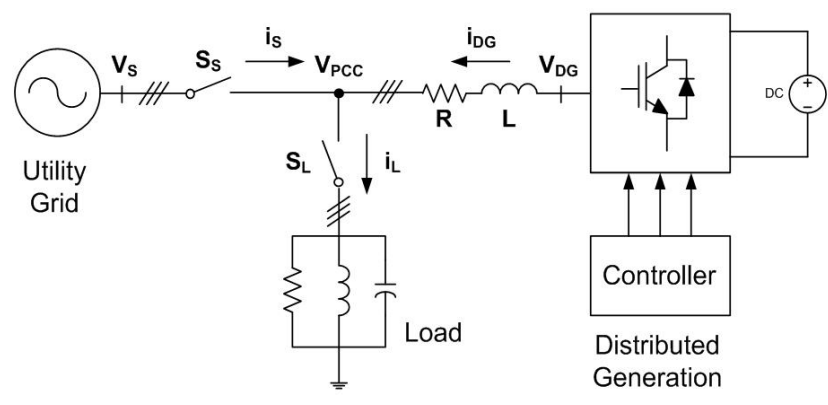

Fig. 3. Configuration of Grid-tied DG with Inverter.

grid using a PLL (phase-locked loop) module and controls the active and reactive powers supplied at the PCC.

The active and reactive powers are controlled on the $d-q$ transformed coordinates. The instantaneous active and reactive powers at the PCC are represented by the following equations:

$$
\begin{aligned}
p & =\frac{3}{2} v_{p c c_{-} d} \cdot i_{D G_{-} d} \\
q & =\frac{3}{2} v_{p c c_{-} d} \cdot i_{D G_{-} q} .
\end{aligned}
$$

Where, $V_{P C C_{-} d}$ is the peak value of voltage at the PCC, and $i_{D G_{-} d}$ and $i_{D G_{-} q}$ are the direct and quadrature components of inverter output current.

Equation (1) and (2) show that $p$ and $q$ can be controlled independently with $i_{D G_{-} d}$ and $i_{D G_{-} q}$.

The dynamic equation for a grid-tied inverter system can be expressed by the following equation using Kirchhoff's voltage rule:

$$
\frac{d i_{D G \_a b c}}{d t}=-\frac{R}{L} i_{D G \_a b c}+\frac{1}{L} v_{D G \_a b c}-\frac{1}{L} v_{p c c \_a b c} .
$$

Assuming that a 3-phase power system is balanced, the above equation can be expressed on the $\mathrm{d}-\mathrm{q}$ coordinates like equations (4) and (5).

$$
\begin{gathered}
\frac{d}{d t}\left[\begin{array}{l}
i_{D G \_} d \\
i_{D G \_} q
\end{array}\right]=\left[\begin{array}{cc}
-\frac{R}{L} & \omega_{0} \\
-\omega_{0} & -\frac{R}{L}
\end{array}\right]\left[\begin{array}{l}
i_{D G \_} d \\
i_{D G \_} q
\end{array}\right]+\frac{1}{L}\left[\begin{array}{l}
v_{D G \_}-v_{p c c_{-} d} \\
v_{D G_{-} q}-v_{p c c_{-} q}
\end{array}\right] \\
\frac{d}{d t}\left[\begin{array}{l}
i_{D G_{-} d} \\
i_{D G_{-} q}
\end{array}\right]=\left[\begin{array}{cc}
-\frac{R}{L} & 0 \\
0 & -\frac{R}{L}
\end{array}\right]\left[\begin{array}{l}
i_{D G_{-} d} \\
i_{D G_{-} q}
\end{array}\right]+\frac{1}{L}\left[\begin{array}{l}
v_{R L_{-} d} \\
v_{R L_{-} q}
\end{array}\right]
\end{gathered}
$$

where:

$$
\begin{aligned}
& v_{R L_{-} d}=v_{D G_{-} d}-v_{p c c_{-} d}+\omega_{0} L i_{D G_{-} q} \\
& v_{R L_{\_} q}=v_{D G_{-} q}-v_{p c c_{-} q}-\omega_{0} L i_{D G_{-} d} .
\end{aligned}
$$

Since equation (5) has a decoupled nature, independent control of $i_{D G_{-} d}$ and $i_{D G_{-} q}$ is possible, which means that independent control of $p$ and $q$ is also possible.

The above equations can be utilized to design a typical controller for a voltage source inverter, which is shown in Fig. 4.

By expressing equation (5) in the s-domain, the following two equations are derived:

$$
\begin{aligned}
& i_{D G_{-} d}=\frac{1}{s L_{f}+R_{f}} v_{R L_{-} d} \\
& i_{D G_{-} q}=\frac{1}{s L_{f}+R_{f}} v_{R L_{-} q} .
\end{aligned}
$$




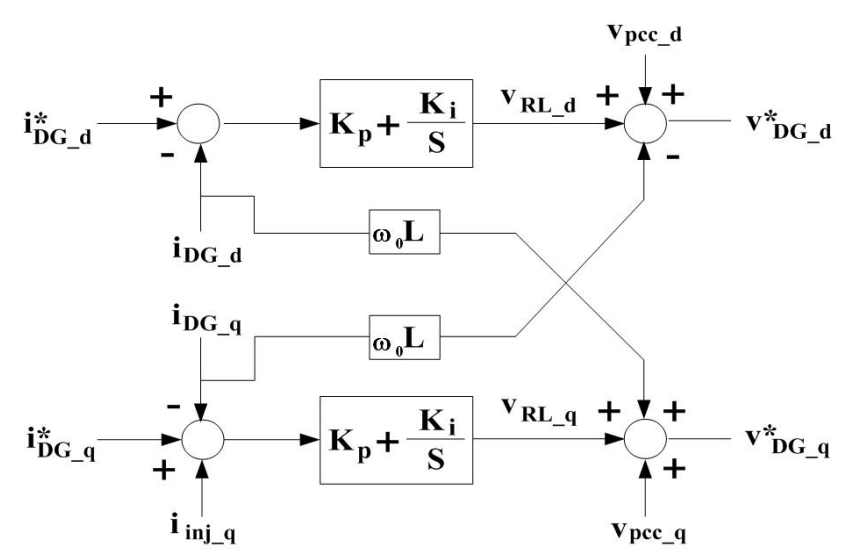

Fig. 4. Typical Controller for Voltage Source Inverter.

\section{ReACtive CurRent InJECTION}

When a disturbed current $i_{i n j \_q}(t)$ is injected into the qcomponent, the steady state converter current on the $\mathrm{d}-\mathrm{q}$ coordinates can be expressed by the following equation:

$$
\left[\begin{array}{c}
i_{D G_{-} d} \\
i_{D G_{-} q}
\end{array}\right]=\left[\begin{array}{c}
i_{D G_{-} d}^{*} \\
i_{D G_{-} q}^{*}+i_{i n j_{-} q}
\end{array}\right]
$$

where, the injected current is a periodic function with respect to time.

If the $R L C$ load tank is pure resistive at $60 \mathrm{~Hz}$, there is no reactive current flow.

$$
\left[\begin{array}{c}
i_{D G_{-} d} \\
i_{D G_{-} q}
\end{array}\right]=\left[\begin{array}{c}
i_{D G_{-} d}^{*} \\
i_{\text {inj_q }}
\end{array}\right] .
$$

The above current values can be expressed in the $a b c$ coordinates as the following equation:

$\left[\begin{array}{l}i_{D G_{\_} a} \\ i_{D G_{-} b} \\ i_{D G_{-} c}\end{array}\right]=\left[\begin{array}{c}i_{D G_{-} d}^{*} \cdot \cos \left(\omega_{0} t\right)-i_{\text {inj_q }} \cdot \sin \left(\omega_{0} t\right) \\ i_{D G_{\_} d}^{*} \cdot \cos \left(\omega_{0} t-\frac{2}{3} \pi\right)-i_{i n j_{-} q} \cdot \sin \left(\omega_{0} t-\frac{2}{3} \pi\right) \\ i_{D G_{-} d}^{*} \cdot \cos \left(\omega_{0} t+\frac{2}{3} \pi\right)-i_{i n j_{q} q} \cdot \sin \left(\omega_{0} t+\frac{2}{3} \pi\right)\end{array}\right]$.

If the injected current $i_{i n j_{-} q}(t)$ is assumed to be $I_{d} \cos \left(\omega_{d} t\right)$, the phase-A current $i_{D G_{-} a}$ can be represented as the following:

$$
\begin{gathered}
i_{D G \_a}=i_{D G \_d}^{*} \cdot \cos \left(\omega_{0} t\right)-I_{d} \cdot \cos \left(\omega_{d} t\right) \cdot \sin \left(\omega_{0} t\right) \\
i_{D G \_a}=i_{D G_{-} d}^{*} \cdot \cos \left(\omega_{0} t\right)-\frac{1}{2} I_{d} \cdot\left[\sin \left(\omega_{1} t\right)+\sin \left(\omega_{2} t\right)\right]
\end{gathered}
$$

where, the frequency is defined as follows:

$$
\begin{aligned}
& \omega_{1}=\omega_{0}-\omega_{d} \\
& \omega_{2}=\omega_{0}+\omega_{d} .
\end{aligned}
$$

The sideband current at the frequencies $\omega_{1}$ and $\omega_{2}$ flows through the low-impedance path formed by the utility grid before islanding occurs. The post-islanding voltage at the PCC can be represented as the superposition of three components at $\omega_{0}, \omega_{1}$ and $\omega_{2}$ as follows:

$v_{P C C_{-} a}=v_{0} \cdot \cos \left(\omega_{0} t\right)-v_{1} \cdot \sin \left(\omega_{1} t+\alpha\right)-v_{2} \cdot \sin \left(\omega_{2} t+\beta\right)$

where:

$$
v_{0}=R i_{D G_{-} d}^{*}
$$

$$
\begin{aligned}
v_{1} & =\frac{I_{d}}{2 \sqrt{\left(\frac{1}{R}\right)^{2}+\left(\omega_{1} C-\frac{1}{\omega_{1} L}\right)^{2}}} \\
v_{2} & =\frac{I_{d}}{2 \sqrt{\left(\frac{1}{R}\right)^{2}+\left(\omega_{2} C-\frac{1}{\omega_{2} L}\right)^{2}}} \\
\alpha & =-\tan ^{-1}\left[\frac{R\left(\omega_{1}^{2} L C-1\right)}{\omega_{1} L}\right] \\
\beta & =-\tan ^{-1}\left[\frac{R\left(\omega_{2}^{2} L C-1\right)}{\omega_{2} L}\right] .
\end{aligned}
$$

The above equations imply that the voltage at the PCC has a frequency deviation if the injected current $i_{\text {inj_q }}(t)$ is a periodic function.

\section{Cross-Correlation IndEX}

There are several methods which have already been proposed by other researchers. One typical method is to inject a sine-wave or square-wave reactive current with a frequency lower than $60 \mathrm{~Hz}$ and a $5 \%$ rated current. However, the injection of a $5 \%$ reactive current might affect the power factor and the harmonic level at the point of common connection. In this paper a triangular reactive current with a $20 \mathrm{~Hz}$ frequency and a $1 \%$ rated current is injected in order to avoid disturbance against the utility grid and confusion with harmonic noise.

Since the injected reactive power is small, the frequency deviation is also small, which might offer difficulty in detecting islanding. To solve this weak point, a cross-correlation method is applied in which the injected reactive current is correlated by the resulted frequency deviation.

Cross-correlation is a very effective method to evaluate the similarity of two signals $x_{1}(n)$ and $x_{2}(n)$ in the point of energy. A cross-correlation sequence $C_{x 1 x 2}(k)$ for two signals can be represented by equation (23).

$$
C_{x_{1} x_{2}}(k)=\sum_{n=-\infty}^{\infty} x_{1}(n) x_{2}(n+k),(k=0, \pm 1, \pm 2, \ldots, m) .
$$

In order to apply a cross-correlation sequence for islanding detection, the reactive current $I_{i n j_{-} q}(n)$ is assigned to $x_{1}(n)$, while the frequency deviation $\Delta f_{P C C}$ is assigned to $x_{2}(n+k)$.

The reactive current $I_{i n j_{-} q}(n)$ has 500 data in one period of a triangular waveform. Based on these data, a total of 50,000 times of multiplication and addition has to be carried out for the calculation of a cross-correlation sequence.

Assuming that a floating point DSP TMS320vc33 is used, the processing time for calculating the cross-correlation sequence is $3.25 \mathrm{~ms}$ based on an instruction time of $13 \mathrm{~ns}$.

A sampling time of $100 \mathrm{~ms}$ is too fast to implement realtime calculation of a cross-correlation sequence. In order to solve this problem, a sampling time of $500 \mathrm{~ms}$ was selected, which reduced the computation time down to $130 \mathrm{~ms}$. The computation of a cross-correlation sequence is carried out once for each period of DSP computation frequency and it proceeds with a sliding window pattern.

Equation (23) is a general form to compute a crosscorrelation sequence when the two signals are not periodic. In our case both signals are periodic. So, only positive values 
TABLE I

CIRCUit PARAMETERS FOR Simulation

\begin{tabular}{|l|l|l|}
\hline \multirow{3}{*}{ Source } & Rated voltage & $220 \mathrm{~V}$ \\
\cline { 2 - 3 } & Rated frequency & $60 \mathrm{~Hz}$ \\
\hline \multirow{4}{*}{ Distributed Generation } & Rated power & $20 \mathrm{~kW}$ \\
\cline { 2 - 3 } & Rated voltage & $220 \mathrm{~V}$ \\
\cline { 2 - 3 } & Switching frequency & $10 \mathrm{kHz}$ \\
\cline { 2 - 3 } & DC-link voltage & $450 \mathrm{~V}$ \\
\cline { 2 - 3 } & Coupling reactor & $2 \mathrm{mH}$ \\
\hline Load & Rated power & $20 \mathrm{kVA}(\mathrm{Q}=2.0)$ \\
\hline
\end{tabular}

for $n$ are considered. Also the maximum number $\mathrm{N}$ is equal to 100 , considering a sampling time of $500 \mathrm{~ms}$.

$$
C_{x_{1} x_{2}}(k)=\sum_{n=0}^{100} I_{q_{-} i n j}(n) \Delta f_{P C C}(n+k),(k=0, \pm 1, \ldots, \pm 25)
$$

where, the cross-correlation sequence is obtained through the multiplication of the injected reactive current by the frequency deviation, and the addition of all the results calculated from $n=0$ to $n=100$.

A normalized cross-correlation sequence $C_{n o r m}(k)$ is obtained using equation (25), in which the maximum value is defined as an islanding detection index.

$$
C_{\text {norm }}(k)=\frac{1}{K_{\text {nor }}} \frac{1}{100} C_{x_{1} x_{2}}(k),(k=0, \pm 1, \ldots, \pm 25)
$$

where, $K_{n o r}$ is a normalized constant of 0.03748 , calculated in off-line manner.

\section{Simulation}

Various computer simulations with PSCAD/EMTDC software were carried out to verify the feasibility of the proposed islanding detection method. The power circuit is represented using the built-in models supplied by the software manufacturer. The controller which consists of a PLL, a d-q transform, and a current control algorithm are represented using userdefined models coded in C-language, as well as the islanding detection method with signal cross-correlation. Table I shows the circuit parameters used in the simulation.

In order to achieve a simulation accuracy that is as close as the hardware experiment, the reference signal is compared with the carrier every $100 \mu \mathrm{s}$, which is one period of a $10 \mathrm{kHz}$ switching frequency. The PWM pulse generation is synchronized with the control period and the inverter output voltage is synchronized with the utility grid through the PLL.[12]

When the size of the load is almost equal to the output power of the DG, the deviation of the measured voltage and the frequency at the point of common connection is rather small. Therefore, it is very difficult to detect the islanding state. In this simulation, it should be confirmed that the proposed method is effective at detecting the islanding state inside the NDZ.

Fig. 5 shows the simulation results which confirm that the grid-tied power system operates inside the NDZ, when it has fallen into the islanding state. The variations of the voltage and the frequency were measured from $0.4 \mathrm{sec}$ to $1.2 \mathrm{sec}$ to check the operation inside the NDZ. The current control of the DG starts at $0.2 \mathrm{sec}$ and the islanding state occurs at $0.5 \mathrm{sec}$ by

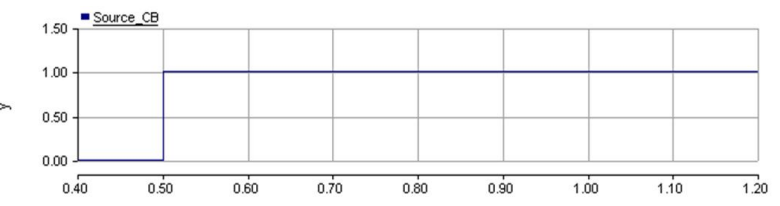

(a) $\mathrm{CB}$ opening signal for islanding.

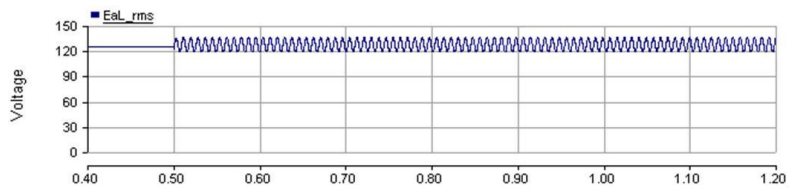

(b) RMS phase voltage.

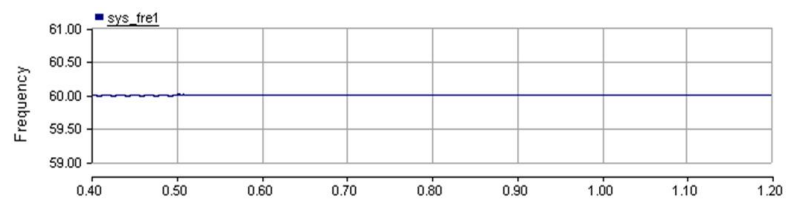

(c) Frequency variation at the connection point.

Fig. 5. Verification for System Operation inside NDZ.

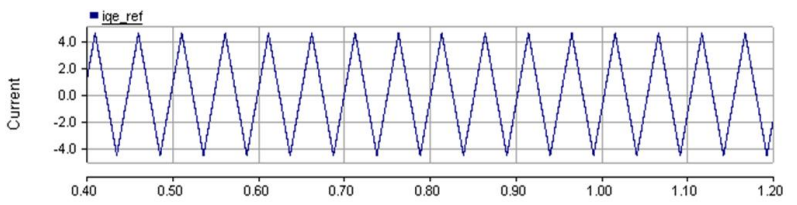

(a) Injected reactive current of $5 \%$ to the rated value.

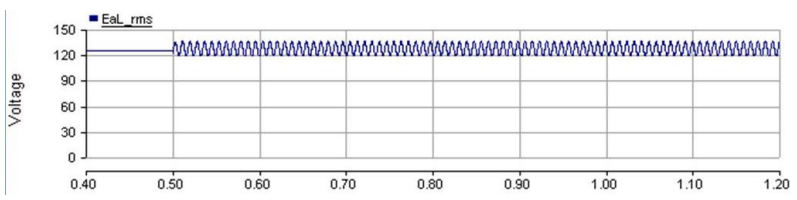

(b) RMS phase-voltage variation.

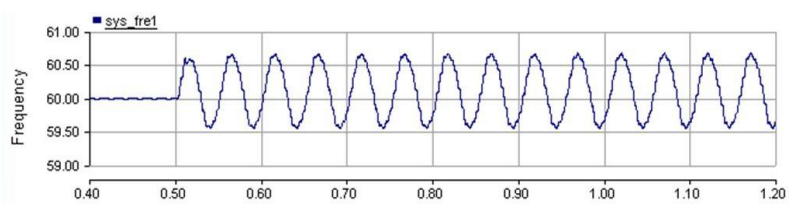

(c) Power frequency variation.

Fig. 6. Frequency Detection due to Reactive Current Injection.

opening the circuit breaker connected to the power system as shown in Fig. 5(a).

Fig. 5(b) shows the variations in the RMS phase-voltage at the point of common connection. It is confirmed that the RMS phase-voltage is located between $0.88<V_{P C C}<1.10 \mathrm{pu}$.

Fig. 5(c) shows that the power frequency is located between $59.3<f_{P C C}<60.5 \mathrm{~Hz}$. Therefore, it is verified that the grid-tied DG system operates inside the NDZ.

Fig. 6 shows the variations in the phase voltage and the frequency deviation by injecting a 5\% reactive current to the rated current of a $20 \mathrm{kVA}$ system. The maximum reactive current is about $4.5 \mathrm{~A}$ on the coordinate system shown in Fig. 6(a).

Fig. 6(b) shows the variations in the RMS phase-voltage according to the injected reactive current. It is confirmed that the RMS phase-voltage is located between $0.88<V_{P C C}<1.10 \mathrm{pu}$. 


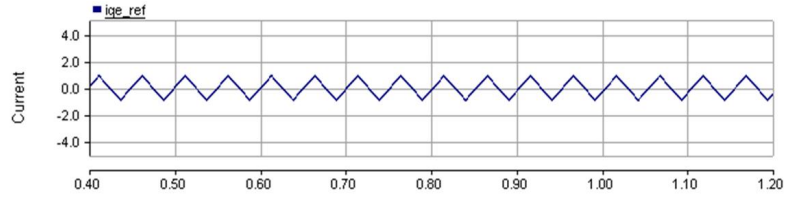

(a) Injected reactive current of $1 \%$ to the rated value.

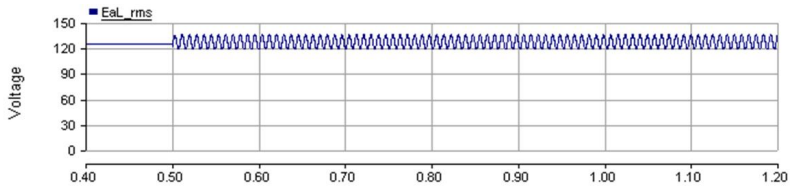

(b) RMS phase-voltage variation.

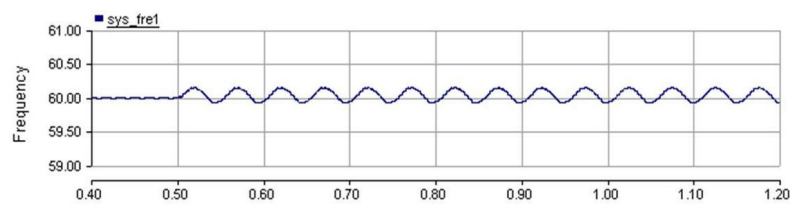

(c) Power frequency variation.

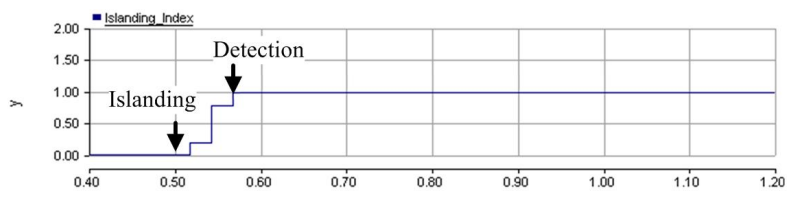

(d) Cross-correlation index.

Fig. 7. Cross-correlation Index for Islanding Detection.

Fig. 6(c) shows the variations in the power frequency, which are negligible before the islanding occurs at $0.5 \mathrm{sec}$, but suddenly grow right after the islanding occurs. The power frequency is located outside the region of $59.3<f_{P C C}<60.5 \mathrm{~Hz}$. Therefore, the islanding can be easily detected by measuring the frequency change.

Fig. 7 shows the variations in each parameter when the cross-correlation method is applied for the detection of the islanding state. The maximum value of the triangular reactive current is $1 \%$ of the rated current, which is about $0.909 \mathrm{~A}$ on the coordinate system shown in Fig. 7(a).

Fig. 7(b) shows the variations in the RMS phase-voltage according to the injected reactive current. It is confirmed that the RMS phase-voltage is located between $0.88<V_{P C C}<1.10 \mathrm{pu}$.

Fig. 7(c) shows the variations in the power frequency, which are negligible before the islanding occurs at $0.5 \mathrm{sec}$, but grow suddenly after the islanding occurs at $0.5 \mathrm{sec}$. However, the power frequency is still located between $59.3<f_{P C C}<60.5 \mathrm{~Hz}$. Therefore, it is impossible to detect the islanding state by measuring the frequency change.

Fig. 7(d) shows the normalized discrimination index for islanding detection by doing a cross-correlation of the injected reactive current and the frequency deviation signal. The index value goes up to $0.8 \mathrm{pu}$ at $0.54 \mathrm{sec}$, and up to 1.04 at $0.56 \mathrm{sec}$. It is defined that the islanding state is discriminated when the cross-correlation index is larger than 0.5. Therefore, it is realized that the proposed cross-correlation method shows reasonable performance within the NDZ.
TABLE II

CIRCUIT PARAMETERS FOR EXPERIMENT

\begin{tabular}{|l|l|l|}
\hline \multirow{4}{*}{ Source } & Rated voltage & $380 \mathrm{~V}$ \\
\cline { 2 - 3 } & Rated frequency & $60 \mathrm{~Hz}$ \\
\cline { 2 - 3 } & Transformer & $380 / 220 \mathrm{~V}$ \\
\hline \multirow{4}{*}{ Distributed Generation } & Rated voltage & $220 \mathrm{~V}$ \\
\cline { 2 - 3 } & Rated power & $3 \mathrm{~kW}$ \\
\cline { 2 - 3 } & Switching frequency & $10 \mathrm{kHz}$ \\
\cline { 2 - 3 } & DC-link voltage & $450 \mathrm{~V}$ \\
\cline { 2 - 3 } & Coupling reactor & $2.5 \mathrm{mH}$ \\
\hline Load & Rated power & $3.5 \mathrm{kVA}(\mathrm{Q}=2.0)$ \\
\hline
\end{tabular}

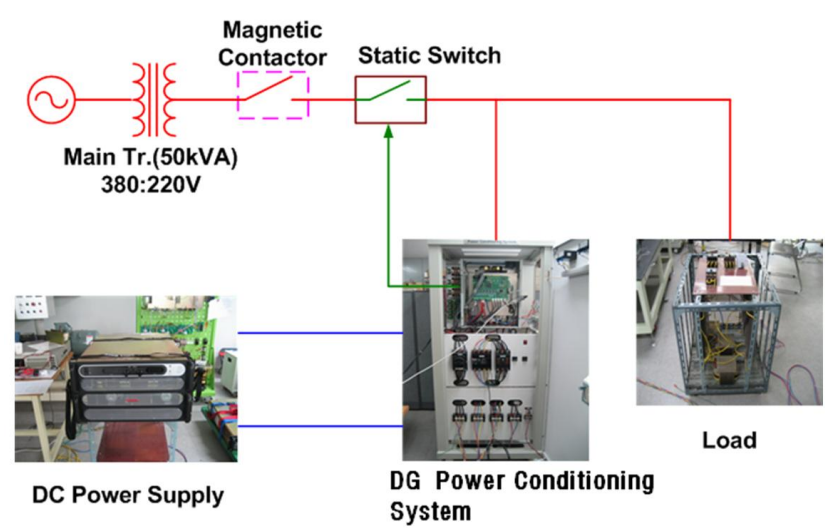

Fig. 8. Configuration of Experimental Set-up.

\section{SCALED MOdEL EXPERIMENT}

A hardware prototype was built and tested to verify the feasibility of the proposed islanding detection method. Actually, the ideal value of the source impedance, the load parameter, and the other circuit parameters were used in the simulation. Therefore, the proposed method might not be effective in an actual hardware experiment because of the variation of circuit parameters and the ripple in the current control, which affect the calculation of the index. Various experimental works were carried out to confirm that the proposed method is effective in the real environment.

Table II shows the circuit parameters that are used in the experimental studies.

Fig. 8 shows the hardware arrangement for an experiment to verify the proposed islanding detection method. The source is provided from a $380 \mathrm{~V} / 220 \mathrm{~V} 50 \mathrm{kVA}$ distribution transformer through a distribution circuit breaker for generating the islanding state. Behind the circuit breaker, a load and an inverter with a DC power source are connected. The distributed generation is modeled with an inverter and a DC power supply. The rated output voltage of the inverter-based DG is $220 \mathrm{~V}$ and the DC source voltage is $450 \mathrm{~V}$.

The inverter-based DG interconnected with the utility grid has a floating-point DSP (digital signal processor) controller, in which the proposed detection algorithm is programmed in the C-language and down-loaded through an emulator. The configuration of the developed control board is shown in Fig. 9. The DSP control board was designed using a TMS320vc33 chip for real time operation and an EPLD chip for PWM logic implementation. There are two external memory chips, two A/D converter chips, and one D/A chip.

As analyzed in the simulations, the size of the load is adjusted to be same as the power rating of the DG, so that 




Fig. 9. DSP Control Board based on TMS320vc33.

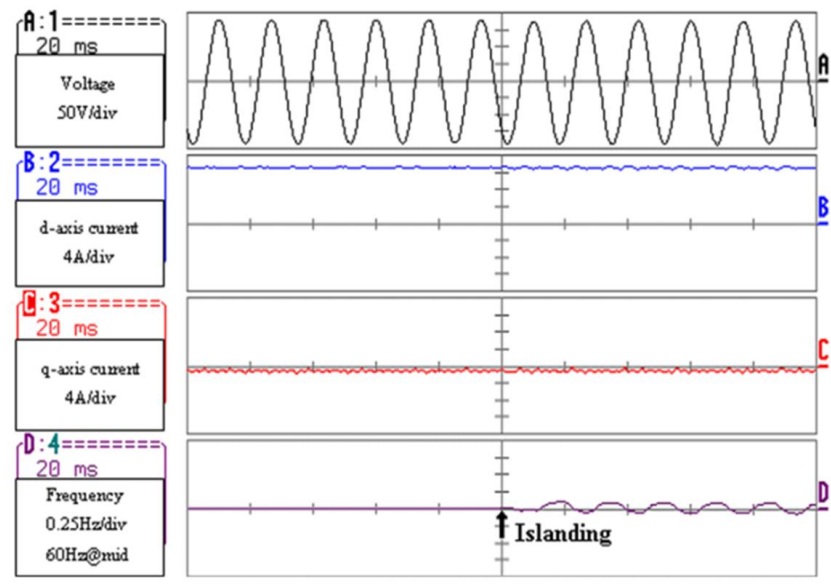

Fig. 10. Verification for Operational inside NDZ.

the system operates inside the NDZ. The phase-voltage and the power frequency at the PCC should be located between $0.8<V_{P C C}<1.10 \mathrm{pu}$ and $59.3<f_{P C C}<60.5 \mathrm{~Hz}$, without escaping for $0.5 \mathrm{sec}$.

The reference value of the active current on the $\mathrm{d}$ axis was set to $13.2 \mathrm{~A}$ so as to satisfy the islanding condition. The reference value of the reactive current on the $\mathrm{q}$ axis was set to $0.65 \mathrm{~A}$ in order to compensate the reactive power required at the coupling reactor and the transformer.

Fig. 10 shows the phase-voltage at the point of common connection, the active and reactive currents, and the frequency variation when the power system operates inside the NDZ. The phase-voltage at the point of common connection is maintained at the nominal value after the islanding occurs. Both the active and reactive currents are respectively maintained at a constant value. The frequency change is located within $0.25 \mathrm{~Hz}$ after the islanding occurs. It is clear that the hardware circuit parameters were properly determined so as to operate inside the NDZ.

Fig. 11 shows the injected reactive current, the active current, and the frequency variations before and after the islanding occurs. The magnitude of the frequency variations increases right after the islanding occurs.

Fig. 12 shows the phase-voltage at the point of common connection, the injected reactive current, the frequency variations, and the cross-correlation index. The system frequency

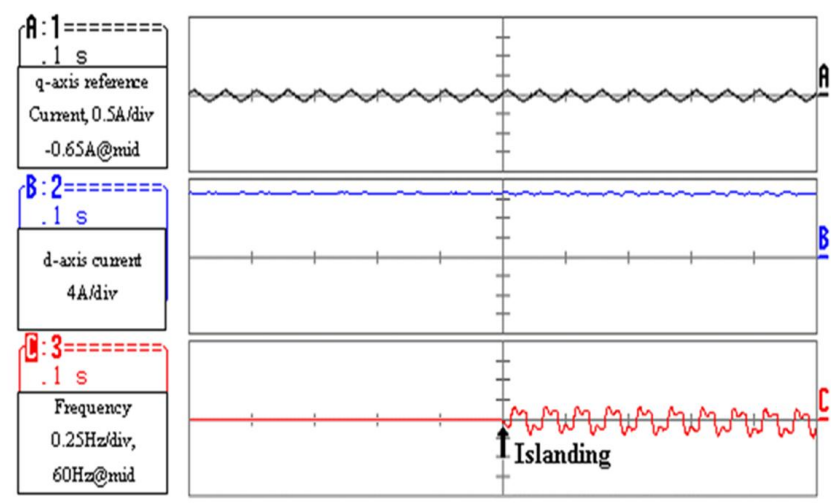

Fig. 11. Frequency Deviation before and after Islanding.

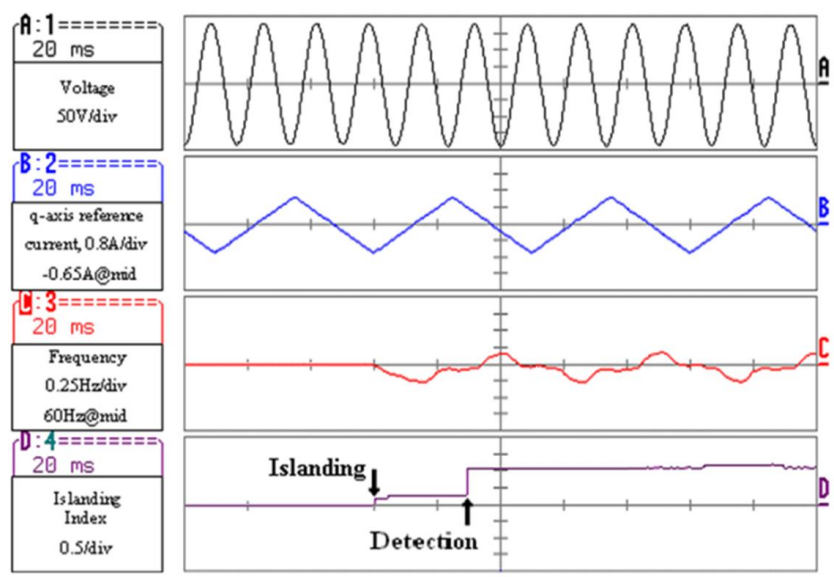

Fig. 12. Islanding Index through Cross-correlation.

starts to change at the instant of islanding, of which the magnitude is about $0.1 \mathrm{~Hz}$. The cross-correlation index goes up to $1.0 \mathrm{pu}$ after the elapsing of $30 \mathrm{~ms}$ from the instant of islanding, even though there is a unevenness when compared with the simulation results. Therefore, it is clear that the islanding state can be easily detected inside the NDZ by the proposed cross-correlation method.

\section{CONCLUSION}

This paper describes a new islanding detection method for inverter-based DGs. The developed method uses the signal cross-correlation scheme between the injected reactive current and the power frequency deviation.

The developed method injects $1 \%$ of the reactive current to the rated current which brings about a negligible degradation of power quality. The developed method detects the islanding state by calculating the cross-correlation index between the injected reactive current and the frequency deviation.

The operational feasibility of the proposed method was verified through computer simulations with PSCAD/EMTDC software, and experimental work with a hardware prototype. It is demonstrated that the proposed method can detect the islanding state effectively without degrading the power quality at the PCC.

Further study is required to overcome the cancellation of the injected reactive current in multiple DGs interconnected with the utility grid. 


\section{ACKNOWLEDGMENT}

This work was supported by the Basic Science Research Program through the National Research Foundation of Korea (NRF) funded by the Ministry of Education, Science and Technology (2010-0029428).

\section{REFERENCES}

11] M. E. Ropp, M.Begovic, and A.Robatgi, "Analysis and performance assessment of the active frequency drift method of islanding prevention," IEEE Trans. Energy Convers., Vol. 14, No. 3, pp.810-816, Sep. 1999.

[2] M. E. Ropp, M. Begovic, A. Rohatgi, "Determining the relative effectiveness of islanding prevention techniques using phase criteria and non-detection zones," IEEE Transactions on Energy Conversion, Vol. 15, No. 3 , pp. 290-296, Sep. 2000.

[3] W. Bower and M. Ropp, "Evaluation of islanding detection methods for photovoltaic utility-interactive power systems," International Energy Agency, Technical Report IEA PVPS T5-09, Mar. 2002.

[4] IEEE Std. 929-2000, IEEE Recommended Practice for Utility Interface of Photovoltaic(PV) Systems, Sponsored by IEEE Standards Coordinating Committee 32 on Photovoltaics, IEEE Std. 929-2000, Published by the IEEE, New York, NY, Apr. 2000.

[5] S. Juang and F. Pai, "A new approach to islanding detection of dispersed generators with self-commutated static power converters," IEEE Trans. Power Delivery, Vol. 15, No. 1, pp. 500-507, Apr. 2000.

[6] G.K. Hung, C.C Chang, and C.L. Chem, "Automatic phase-shift method for islanding detection of grid-connected photovoltaic inverters," IEEE Trans. Energy Conversion, Vol. 18, No. 1, pp. 169-173, Mar. 2003.

[7] V. John, Z. Ye, and A. Kolwalkar, "Investigation of anti-islanding protection of power converter based distributed generators using frequency domain analysis," in Proc. IEEE Power Eng. Society General Meeting, Vol. 4, pp. 2452-2458, Jul. 2003.

[8] R. A. Walling and N. W. Miller, "Distributed generation islanding implications on power system dynamic performance," in Proc. IEEE Power Eng. Soc. Summer Meeting, Vol. 1, pp. 92-96, Jul. 2002.

[9] S. Jang and K. Kim, "An islanding detection method for distributed generations using voltage unbalance and total harmonic distortion of current," IEEE Trans. Power Delivery, Vol. 19, No. 1, pp. 745-752, Apr. 2004.

[10] F. Katiraei, M. R. Iravani, and P. W. Lehn, "Micro-grid autonomous operation during and subsequent to islanding process," IEEE Trans. Power Del., Vol. 20, No. 1, pp. 248-257, Jan. 2005.
[11] G. Hernande-Gonzalez and R. Iravani, "Current Injection for Active Islanding Detection of Electronically-Interfaced Distributed Resources," IEEE Trans on Power Delivery, Vol. 21, No. 3, Jul. 2006

[12] B. Han and B. Bae, "Novel Phase-Locked Loop Using Adaptive Linear Combiner," IEEE Trans on Power Delivery, Vol. 21, No. 1, Jan. 2006.

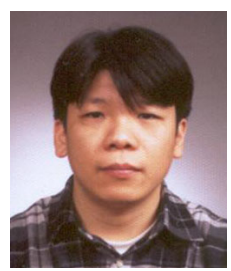

Byung-Yeol Bae received his B.S., M.S., and Ph.D. in Electrical Engineering from Myongji University in 2001, 2003, 2007, respectively. He is currently a Principal Research Engineer at the LS Industrial Systems Co., Ltd. His research interests include power electronics applications for custom power, distributed generation and HVDC.

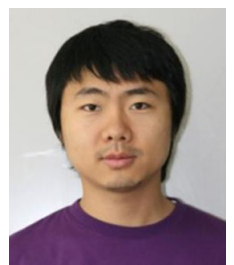

Jong-Kyou Jeong received his B.S. and M.S. in Electrical Engineering from Myongji University, Korea, in 2008,2010 , respectively. He is currently working toward his Ph.D. at Myongii University. His research interests include power electronics applications for custom power and distributed generation.

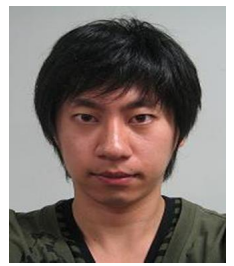

Ji-Heon Lee received his B.S. in Electrical Engineering from Myongji University, Korea, in 2008. He is currently working toward his Ph.D. at Myongji University. His research interests include power electronics applications for custom power and distributed generation.

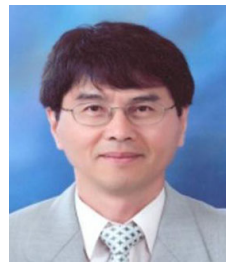

Byung-Moon Han (S'91-M'92-SM'00) received his B.S. in Electrical Engineering from Seoul National University, Korea, in 1976, and his M.S. and Ph.D. from Arizona State University in 1988 and 1992, respectively. He was with the Westinghouse Electric Corporation as a Senior Research Engineer in the Science and Technology Center. Currently he is a Professor in the Department of Electrical Engineering at Myongji University, Korea. His research interests include power electronics applications for FACTS, custom power, and distributed generation. 